Article

\title{
Almost Periodic Solutions of First-Order Ordinary Differential Equations
}

\author{
Seifedine Kadry ${ }^{1, *(\mathbb{D}}$, Gennady Alferov ${ }^{2}\left(\mathbb{D}\right.$, Gennady Ivanov ${ }^{2}$ and Artem Sharlay ${ }^{2}(\mathbb{D})$ \\ 1 Department of Mathematics and Computer Science, Faculty of Science, Beirut Arab University, \\ Beirut, P.O. Box 11-5020, Lebanon \\ 2 Saint Petersburg State University, Universitetskaya nab. 7-9, 199034 Saint Petersburg, Russia; \\ g.alferov@spbu.ru (G.A.); guennadi.ivanov@gmail.com (G.I.); a.sharlay@spbu.ru (A.S.) \\ * Correspondence: s.kadry@bau.edu.lb
}

Received: 22 August 2018; Accepted: 14 September 2018; Published: 17 September 2018

\begin{abstract}
Approaches to estimate the number of almost periodic solutions of ordinary differential equations are considered. Conditions that allow determination for both upper and lower bounds for these solutions are found. The existence and stability of almost periodic problems are studied. The novelty of this paper lies in the fact that the use of apparatus derivatives allows for the reduction of restrictions on the degree of smoothness of the right parts. In our work, regarding the number of periodic solutions of equations first order, we don't require a high degree of smoothness and no restriction on the smoothness of the second derivative of the Schwartz equation. We have all of these restrictions lifted. Our new form presented also emphasizes this novelty.
\end{abstract}

Keywords: ODE; periodic solutions; upper bounds; lower bounds; stability

\section{Introduction}

In the works of Lebedeva [1], regarding the number of periodic solutions of equations first order, they required a high degree of smoothness. Franco et al. required the smoothness of the second derivative of the Schwartz equation [2]. We have all of these restrictions lifted. Our new form presented also emphasizes this novelty.

There are two classes of oscillatory processes, periodic and non-periodic. In theory and practice, an intermediate class of almost periodic oscillations is of great importance.

Almost periodic oscillations are oscillations that are close to periodic oscillations, which are composed of harmonics with incommensurable periods. The process, which consists of the sum of two periodic oscillations with incommensurate frequencies, is also an almost periodic oscillation.

The theory of almost periodic oscillations began to develop in the works of the Latvian mathematician P.G. Bol, the Danish mathematician H.A. Bohr, and others.

Bol [3] laid the foundations of almost periodic functions theory and quasiperiodic functions theory, proved the theorem on the decomposability of quasiperiodic functions in a Fourier series and the theorem on a quasiperiodic function.

Harald Bohr's scientific papers relate mainly to functions theory. He made a great contribution to development of the almost periodic functions theory [4]. Uniform almost periodic functions are named after Harald Bohr.

Fundamental results in the theory of periodic and almost periodic oscillations obtained in the works of V.A. Pliss [5].

In many problems of classical mechanics, celestial mechanics, robotics, and mechatronics, there are processes in which the time dependence is not periodic, but they can be expressed through 
trigonometric sums. In this connection, interest has arisen in the study of almost periodic solutions of differential equations and differential equations with almost periodic coefficients [6-14].

Over the last years, the question of studying almost periodic functions in robotics [15-21], dynamic systems [22-26], stability theory [27-31], control systems for space objects [32-34], and economy problems [35-38] arose significantly.

\section{Upper Bound for Number of Almost Periodic Solutions}

Let the right-hand side of equation be

$$
\dot{x}=f(t, x) .
$$

Theorem 1. If the right-hand side of Equation (1) for each fixed $t$ is an increasing function with respect to $x$, and there exists an instant $t^{*}$, such that $f\left(t^{*}, x\right)$ is strictly increasing, then Equation (1) can have at most one almost periodic solution.

Proof. Suppose that the conditions of the theorem are satisfied, and conversely that Equation (1) has two almost periodic solutions, $\varphi\left(t, x_{1}\right)$ and $\varphi\left(t, x_{2}\right)$, starting at $t=0$ at $x_{1}$ and $x_{2}$, respectively. It can be proven that solutions $\varphi\left(t, x_{1}\right)$ and $\varphi\left(t, x_{2}\right)$ do not intersect [35], and therefore, without loss of generality, the following equation can be assumed to hold for all $t$ :

$$
\varphi\left(t, x_{1}\right)<\varphi\left(t, x_{2}\right) .
$$

Then, by the monotonicity of the function $f$, for all $t$ the following inequality is true:

$$
f\left(t, \varphi\left(t, x_{1}\right)\right) \leq f\left(t, \varphi\left(t, x_{2}\right)\right) .
$$

and for $t=t^{*}$, due to strict increase of the function $f\left(t^{*}, x\right)$ and due to Inequality (2),

$$
f\left(t^{*}, \varphi\left(t^{*}, x_{1}\right)\right)<f\left(t^{*}, \varphi\left(t^{*}, x_{2}\right)\right) .
$$

Without a loss of generality, it can be assumed that $t^{*}>0$.

Let an arbitrary $T>t^{*}$ be taken. Then,

$$
\int_{0}^{T}\left[f\left(t, \varphi\left(t, x_{2}\right)\right)-f\left(t, \varphi\left(t, x_{1}\right)\right)\right] d t=\delta>0 .
$$

Indeed, by (3) $\delta \geq 0$, and from the continuity of the function $f$ it follows that Inequality (4) holds in some neighborhood of point $t^{*}$; consequently the given statement is true.

Let an arbitrary $\varepsilon \in\left(0, \frac{1}{2} \delta\right)$ be taken. By assumption, the functions $\varphi\left(t, x_{1}\right)$ and $\varphi\left(t, x_{2}\right)$ are almost periodic, and consequently they have a common $\varepsilon$-almost period. Hence, there exists $\omega^{\prime} \geq T$, such that

$$
\left|\varphi\left(\omega^{\prime}, x_{1}\right)-x_{1}\right| \leq \varepsilon
$$

and

$$
\left|\varphi\left(\omega^{\prime}, x_{2}\right)-x_{2}\right| \leq \varepsilon
$$


Then, on one hand, from Equation (1) and with regard to Equations (3) and (5), it follows that

$$
\begin{gathered}
{\left[\varphi\left(\omega^{\prime}, x_{2}\right)-x_{2}\right]-\left[\varphi\left(\omega^{\prime}, x_{1}\right)-x_{1}\right]=\int_{0}^{T}\left[f\left(t, \varphi\left(t, x_{2}\right)\right)-f\left(t, \varphi\left(t, x_{1}\right)\right)\right] d t+} \\
\int_{T}^{\omega^{\prime}}\left[f\left(t, \varphi\left(t, x_{2}\right)\right)-f\left(t, \varphi\left(t, x_{1}\right)\right)\right] d t \geq \delta .
\end{gathered}
$$

On the other hand,

$$
\left[\varphi\left(\omega^{\prime}, x_{2}\right)-x_{2}\right]-\left[\varphi\left(\omega^{\prime}, x_{1}\right)-x_{1}\right] \leq \varphi\left(\omega^{\prime}, x_{2}\right)-x_{2}|+| \varphi\left(\omega^{\prime}, x_{1}\right)-x_{1} \mid \leq 2 \varepsilon<\delta .
$$

This contradiction proves that Equation (1) can not have two different almost periodic solutions.

Theorem 2. If the right-hand side of Equation (1) for each fixed $t$ is a function convex in $x$, and there exists a moment $t^{*}$ such that $f\left(t^{*}, x\right)$ is strictly convex, then the Equation (1) can have no more than two almost periodic solutions.

Proof. Suppose that the conditions of the theorem are satisfied, and, conversely, Equation (1) has three almost periodic solutions $\phi\left(t, x_{i}\right), i=1,2,3$ starting at the points $x_{1}, x_{2}, x_{3}$ for $t=0$. In the proof of Theorem 2 [32], it is shown that in the considered situation Equation (1) has the property of existence and uniqueness of solutions, and therefore it is assumed that for all $t$

$$
\phi\left(t, x_{1}\right)<\phi\left(t, x_{2}\right)<\phi\left(t, x_{3}\right) .
$$

Consider two obvious identities, which hold for all $t$ in view of Equation (6):

$$
\frac{\phi^{\prime}\left(t, x_{3}\right)-\phi^{\prime}\left(t, x_{2}\right)}{\phi\left(t, x_{3}\right)-\phi\left(t, x_{2}\right)}=\frac{f\left(t, \phi\left(t, x_{3}\right)\right)-f\left(t, \phi\left(t, x_{2}\right)\right)}{\phi\left(t, x_{3}\right)-\phi\left(t, x_{2}\right)}
$$

and

$$
\frac{\phi^{\prime}\left(t, x_{2}\right)-\phi^{\prime}\left(t, x_{1}\right)}{\phi\left(t, x_{2}\right)-\phi\left(t, x_{1}\right)}=\frac{f\left(t, \phi\left(t, x_{2}\right)\right)-f\left(t, \phi\left(t, x_{1}\right)\right)}{\phi\left(t, x_{2}\right)-\phi\left(t, x_{1}\right)} .
$$

Consider an arbitrary $T>t^{*}$. As noted in the proof of Theorem 1, it can assumed that $t^{*}>0$. Let these equalities be integrated in the limits from 0 to $T$. Then,

$$
P(T)=\ln \frac{\phi\left(T, x_{3}\right)-\phi\left(T, x_{2}\right)}{x_{3}-x_{2}}=\int_{0}^{T} \frac{f\left(t, \phi\left(t, x_{3}\right)\right)-f\left(t, \phi\left(t, x_{2}\right)\right)}{\phi\left(t, x_{3}\right)-\phi\left(t, x_{2}\right)} d t
$$

and

$$
Q(T)=\ln \frac{\phi\left(T, x_{2}\right)-\phi\left(T, x_{1}\right)}{x_{2}-x_{1}}=\int_{0}^{T} \frac{f\left(t, \phi\left(t, x_{2}\right)\right)-f\left(t, \phi\left(t, x_{1}\right)\right)}{\phi\left(t, x_{2}\right)-\phi\left(t, x_{1}\right)} d t .
$$

Subtracting the second equality from the first one, it follows that

$$
\begin{aligned}
& P(T)-Q(T)=\int_{0}^{T}\left[\left(f\left(t, \phi\left(t, x_{3}\right)\right)-f\left(t, \phi\left(t, x_{2}\right)\right)\right)\left(\phi\left(t, x_{3}\right)-\phi\left(t, x_{2}\right)\right)^{-1}-\right. \\
& \left.\left(f\left(t, \phi\left(t, x_{2}\right)\right)-f\left(t, \phi\left(t, x_{1}\right)\right)\right)\left(\phi\left(t, x_{2}\right)-\phi\left(t, x_{1}\right)\right)^{-1}\right] d t .
\end{aligned}
$$

Let the solution $\phi\left(t, x_{2}\right)$ be represented in the following form:

$$
\phi\left(t, x_{2}\right)=\alpha(t) \phi\left(t, x_{1}\right)+(1-\alpha(t)) \phi\left(t, x_{3}\right) .
$$


By Equation (6) it is obvious that $\alpha \in(0,1)$ for all $t$. Substituting the representation of Equation (8) into Equation (7), the following is obtained:

$$
\begin{aligned}
& P(T)-Q(T)=\int_{0}^{T}\left[\alpha(t) f\left(t, \phi\left(t, x_{1}\right)\right)+(1-\alpha(t)) f\left(t, \phi\left(t, x_{3}\right)\right)-\right. \\
& \left.f\left(t, \alpha(t) \phi\left(t, x_{1}\right)+(1-\alpha(t)) \phi\left(t, x_{3}\right)\right)\right]\left[\alpha(t)(1-\alpha(t))\left(\phi\left(t, x_{3}\right)-\phi\left(t, x_{1}\right)\right)\right]^{-1} d t=G(T) .
\end{aligned}
$$

Repeating the arguments presented in the proof of Theorem 2 [32], it is easy to verify that:

$$
G(T)=\delta>0,
$$

while the definition of the function $G$ as well as convexity with respect $x$ of the function $f$ imply that, for any $T^{\prime}>0$,

$$
G\left(T+T^{\prime}\right)=\delta+\delta^{\prime}=G(T)+G\left(T^{\prime}\right)
$$

Besides, $G\left(T^{\prime}\right) \geq 0$.

Consider the functions $P$ and $Q$ once again. It is clear from their definition that they are almost periodic and that

$$
P(0)=Q(0)=0 \text {. }
$$

Consider some $\varepsilon \in\left(0, \frac{1}{2} \delta\right)$ and $\omega^{\prime} \geq T$ such that

$$
\begin{aligned}
& \left|P\left(\omega^{\prime}\right)\right|<\varepsilon, \\
& \left|Q\left(\omega^{\prime}\right)\right|<\varepsilon .
\end{aligned}
$$

Existence of such $\omega^{\prime}$ follows from existence of common $\varepsilon$-almost period for functions $P$ and $Q$ [35].

Then, taking into account the properties of the function $G$ indicated above for $\omega^{\prime}$ taken from (9) it follows that

$$
\left|P\left(\omega^{\prime}\right)-Q\left(\omega^{\prime}\right)\right|=P\left(\omega^{\prime}\right)-Q\left(\omega^{\prime}\right)=G\left(\omega^{\prime}\right)=G(T)+G\left(\omega^{\prime}-T\right) \geq \delta .
$$

On the other hand,

$$
\left|P\left(\omega^{\prime}\right)-Q\left(\omega^{\prime}\right)\right| \leq\left|P\left(\omega^{\prime}\right)\right|+\left|Q\left(\omega^{\prime}\right)\right| \leq 2 \varepsilon<\delta,
$$

so that this contradiction proves the assertion of the theorem.

The next step is to prove the theorem similar to Theorem 3 [32]. Therefore, it is further assumed that the right-hand side of equation

$$
\dot{x}=f(t, x)
$$

is a function continuous on $R^{2}$ that has a continuous on $R^{2}$ derivative with respect to $x, f^{\prime}(t, x)$ that is convex in $x$ for to each fixed $t$, and there exists a moment $t^{*}$ such that $f^{\prime}\left(t^{*}, x\right)$ is strictly convex with respect to $x$. As given above, the solution of Equation (10) starting for $t=0$ at the point $x$ is denoted by $\phi(t, x)$, and assume that

$$
\psi(t, x)=\ln \phi^{\prime}(t, x)=\int_{0}^{t} f^{\prime}(\tau, \phi(\tau, x)) d \tau .
$$

Theorem 3. Assume Equation (10) has two bounded solutions $\phi\left(t, x_{1}\right)$ and $\phi\left(t, x_{2}\right)$, and let $y_{1}<y_{2}$ be two points from $\left[x_{1}, x_{2}\right]$ such that $\phi^{\prime}\left(t, y_{1}\right)$ and $\phi^{\prime}\left(t, y_{2}\right)$ are uniformly bounded. Then a set of functions $\phi^{\prime}(t, y)$, $y \in\left[y_{1}, y_{2}\right]$ is uniformly bounded. 
Proof. The equation in variations implies that

$$
\phi^{\prime}(t, x)=e^{\int_{0}^{t} f^{\prime}(\tau, \phi(\tau, x)) d \tau} \geq 0,
$$

which implies the uniform boundedness below of the functions $\phi^{\prime}(t, y), y \in\left[y_{1}, y_{2}\right]$.

Let us show that the functions $\phi^{\prime}(t, y), y \in\left[y_{1}, y_{2}\right]$, are bounded uniformly from above. Consider an arbitrary point $y \in\left[y_{1}, y_{2}\right]$. It follows from the proof of Theorem 3 [32] that a function $\psi(t, x)$ is convex on $\left[x_{1}, x_{2}\right]$ for any finite $t$. Hence, representing $y$ in the form $y=\alpha y_{1}+(1-\alpha) y_{2}, \quad \alpha \in[0,1]$, gives the following:

$$
\psi(t, y) \leq \alpha \psi\left(t, y_{1}\right)+(1-\alpha) \psi\left(t, y_{2}\right)=\ln \left(\phi^{\prime}\right)^{\alpha}\left(t, y_{1}\right) \phi^{\prime 1-\alpha}\left(t, y_{2}\right) .
$$

Potentiating this inequality and subsituting $\phi^{\prime}\left(t, y_{1}\right)$ by

$$
m \geq \max _{t} \phi^{\prime}\left(t, y_{1}\right)>0,
$$

and $\phi^{\prime}\left(t, y_{2}\right)$ by

$$
n \geq \max _{t} \phi^{\prime}\left(t, y_{2}\right)>0,
$$

the following is obtained:

$$
\phi^{\prime}(t, y) \leq m^{\alpha} n^{1-\alpha} \leq \max _{\alpha \in[0,1]}\left(m^{\alpha} n^{1-\alpha}\right)=k<\infty .
$$

Taking into account the arbitrariness of $t$ and $y$ it becomes obvious that the functions $\phi^{\prime}(t, y)$, $y \in\left[y_{1}, y_{2}\right]$ are uniformly bounded from the above.

Thus, the set of functions $\phi^{\prime}(t, y), y \in\left[y_{1}, y_{2}\right]$ is uniformly bounded from the above and below, so that it is uniformly bounded.

Theorem 4. If the conditions of Theorem 3 are satisfied, then the set of functions $\phi(t, y), y \in\left[y_{1}, y_{2}\right]$ is uniformly bounded and equicontinuous with respect to $y$.

Proof. The uniform boundedness of the functions $\phi(t, y), y \in\left[y_{1}, y_{2}\right] \subset\left[x_{1}, x_{2}\right]$ is provided by the uniqueness property of Equation (10) solutions and the assumption that the solutions $\phi\left(t, x_{1}\right)$ and $\phi\left(t, x_{2}\right)$ are bounded. Their equicontinuity property is caused by the uniform boundedness of the functions $\phi^{\prime}(t, y), y \in\left[y_{1}, y_{2}\right]$, proven in Theorem 3 .

Theorem 5. Let Equation (10) have two bounded solutions $\phi\left(t, x_{1}\right)$ and $\phi\left(t, x_{2}\right), \phi^{\prime}\left(t, x^{*}\right)$ is unbounded for some $x^{*} \in\left(x_{1}, x_{2}\right)$. Then there exists an interval $\left[x^{\prime}, x^{\prime \prime}\right] \ni x^{*}$ such that $\phi^{\prime}(t, x)$ is unbounded for any $x \in\left[x^{\prime}, x^{\prime \prime}\right]$, and for any sequence $\left\{t_{k}\right\}, t_{k} \rightarrow \infty$ as $k \rightarrow \infty$, for which $\phi^{\prime}\left(t_{k}, x^{*}\right) \rightarrow \infty$ as $k \rightarrow \infty$, it is possible to extract a subsequence $\left\{t_{k_{n}}\right\}$ such the sequence of functions $\left\{\phi^{\prime}\left(t_{k_{n}}, x\right)\right\}$ would tend to infinity uniformly with respect to $x \in\left[x^{\prime}, x^{\prime \prime}\right]$ as $n \rightarrow \infty$.

Proof. Consider a sequence $\left\{t_{k}\right\}, t_{k} \rightarrow \infty$ as $k \rightarrow \infty$ such that $\psi\left(t_{k}, x^{*}\right) \rightarrow \infty$ as $k \rightarrow \infty$. Let some $x^{\prime} \in\left(x_{1}, x_{2}\right)$ be fixed, then consider the sequence of functions $\left\{\psi\left(t_{k}, x\right)\right\}, x \in\left[x^{\prime}, x^{*}\right]$. If this sequence of functions tends to infinity uniformly with respect to $x \in\left[x^{\prime}, x^{*}\right]$ as $k \rightarrow \infty$, then interval $\left[x^{\prime}, x^{*}\right]$ is the desired one. Otherwise, there exist $\delta>0$ and a sequence $\left\{x_{k_{n}}\right\} \subset\left[x^{\prime}, x^{*}\right]$ such that

$$
\psi\left(t_{k_{n}}, x_{k_{n}}\right)<\delta \text {. }
$$


Consider an arbitrary point $x^{\prime \prime} \in\left(x^{*}, x_{2}\right)$ and suppose that

$$
\alpha\left(z_{1}, z_{2}\right)=\frac{z_{2}-x^{*}}{z_{2}-z_{1}}, z_{1} \in\left[x^{\prime}, x^{*}\right], z_{2} \in\left[x^{*}, x^{\prime \prime}\right], \alpha\left(x^{*}, x^{*}\right)=1 \text {. }
$$

Consider now arbitrarily large $\Delta>0$ and $N$ being so large that for all $n>N$

$$
\psi\left(t_{k_{n}}, x^{*}\right)>\delta+\Delta
$$

Due to the convexity of the function $\psi(t, x)$, for any finite $n$,

$$
\psi\left(t_{k_{n}}, x^{*}\right) \leq \alpha\left(x_{k_{n}}, x\right) \psi\left(t_{k_{n}}, x_{k_{n}}\right)+\left(1-\alpha\left(x_{k_{n}}, x\right)\right) \psi\left(t_{k_{n}}, x\right), x \in\left[x^{*}, x^{\prime \prime}\right] .
$$

And from the continuity of the function $\psi(t, x)$ and the fact that for $n>N$

$$
\psi\left(t_{k_{n}}, x^{*}\right)>\delta
$$

and

$$
\psi\left(t_{k_{n}}, x_{k_{n}}\right)<\delta
$$

it follows that for all $n>N$

$$
x_{k_{n}} \neq x^{*}
$$

and therefore for all $n>N$

$$
\alpha\left(x_{k_{n}}, x\right) \neq 1, \quad x \in\left[x^{*}, x^{\prime \prime}\right] .
$$

Taking this into account, for any $n>N$ and any $x \in\left[x^{*}, x^{\prime \prime}\right]$ it follows that

$$
\begin{aligned}
& \Delta \leq \psi\left(t_{k_{n}}, x^{*}\right)-\alpha\left(x_{k_{n}}, x\right) \psi\left(t_{k_{n}}, x_{k_{n}}\right) \leq \\
& \frac{\psi\left(t_{k_{n}}, x^{*}\right)-\alpha\left(x_{k_{n}}, x\right) \psi\left(t_{k_{n}}, x_{k_{n}}\right)}{1-\alpha\left(x_{k_{n}}, x\right)} \leq \psi\left(t_{k_{n}}, x\right),
\end{aligned}
$$

i.e., for any $n>N$ and for all $x \in\left[x^{*}, x^{\prime \prime}\right]$

$$
\psi\left(t_{k_{n}}, x\right)>\Delta
$$

The arbitrariness of $\Delta$ implies that on $\left[x^{*}, x^{\prime \prime}\right]$ the functions $\psi\left(t_{k_{n}}, x\right)$ as well as $\phi^{\prime}\left(t_{k_{n}}, x\right)$ tend uniformly with respect to $x$ to infinity as $n \rightarrow \infty$. Thus, $\left[x^{*}, x^{\prime \prime}\right]$ is a desired interval.

The presented theorem proves the following assertion.

Theorem 6. If Equation (10) has two bounded solutions $\phi\left(t, x_{1}\right)$ and $\phi\left(t, x_{2}\right)$, then for any $x \in\left(x_{1}, x_{2}\right)$ function $\phi^{\prime}(t, x)$ is bounded.

Proof. Suppose, on the contrary, that in $\left(x_{1}, x_{2}\right)$, there exists a point $x^{*}$ for which $\phi^{\prime}\left(t, x^{*}\right)$ is unbounded. Then, by Theorem 5 , there exists a sequence $\left\{t_{k}\right\}, t_{k} \rightarrow \infty$ as $k \rightarrow \infty$ and interval $\left[x^{*}, x^{* *}\right] \subset\left(x_{1}, x_{2}\right)$, such that functions $\phi^{\prime}\left(t_{k}, x\right)$ tend to infinity as $k \rightarrow \infty$ uniformly with respect to $x \in\left[x^{*}, x^{* *}\right]$.

Consider two points $x^{\prime}$ and $x^{\prime \prime}$ in $\left[x^{*}, x^{* *}\right]$ and consider the difference $\phi\left(t, x^{\prime \prime}\right)-\phi\left(t, x^{\prime}\right)$. By the Lagrange theorem, for any $k$

$$
\phi\left(t_{k}, x^{\prime \prime}\right)-\phi\left(t_{k}, x^{\prime}\right)=\phi^{\prime}\left(t_{k}, \xi_{k}\right)\left(x^{\prime \prime}-x^{\prime}\right)
$$

where $\xi_{k} \in\left(x^{\prime}, x^{\prime \prime}\right)$. The right-hand side of this equality is unbounded due to the uniform with respect to $x \in\left[x^{*}, x^{* *}\right]$ convergence of the functions sequence $x \in\left[x^{*}, x^{* *}\right]$ to infinity. Hence its left-hand side is also unbounded. But then, in view of the uniqueness of the Equation (10) solutions, there must be at least one of the unbounded functions $\phi\left(t, x_{1}\right)$ or $\phi\left(t, x_{2}\right)$, which contradicts the assumption of 
their boundedness. This contradiction proves that in $\left(x_{1}, x_{2}\right)$ there is no point $x^{*}$ at which the function $\phi^{\prime}\left(t, x^{*}\right)$ would be unbounded.

If we further assumes that Equation (10) has four almost periodic solutions $\phi\left(t, x_{i}\right), i=1,2,3,4$. Since every almost periodic function is bounded, in the case under consideration all the theorems proved above remain valid.

Consider an arbitrary sequence $\left\{\varepsilon_{n}\right\}, \varepsilon_{n} \rightarrow 0$ as $n \rightarrow \infty, \varepsilon_{n}>0$. Let $\omega_{n}$ denote an $\varepsilon_{n}$-almost period of functions $\phi\left(t, x_{i}\right), i=1,2,3,4$. Such $\omega_{n}$ exists, since for a finite number of almost periodic functions for any $\varepsilon>0$, there exists a common $\varepsilon$-almost period [35]. Without loss of generality, it can be assumed that $\omega_{n} \rightarrow \infty$ as $n \rightarrow \infty$.

Theorem 7. If Equation (10) has four almost periodic solutions $\phi\left(t, x_{i}\right), i=1,2,3,4$, then a set of functions $\psi\left(\omega_{n}, x\right), x \in\left[y_{1}, y_{2}\right]$ is uniformly bounded for any interval $\left[y_{1}, y_{2}\right] \subset\left(x_{1}, x_{4}\right)$.

Proof. Consider an arbitrary interval $\left[y_{1}, y_{2}\right] \subset\left(x_{1}, x_{4}\right)$. By Theorem 6 , the functions $\phi^{\prime}\left(t, y_{1}\right)$ and $\phi^{\prime}\left(t, y_{2}\right)$ are bounded, but then a set of functions $\phi^{\prime}(t, x), x \in\left[y_{1}, y_{2}\right]$ is uniformly bounded by Theorem 3 , which implies a uniform boundedness from above of a functions set $\psi(t, x), x \in\left[y_{1}, y_{2}\right]$. Thus, in order to verify the validity of the assertion given in the theorem, it must be proved that a set of functions $\psi\left(\omega_{n}, x\right), x \in\left[y_{1}, y_{2}\right]$ is uniformly bounded from below.

The proof of this assertion involves two steps: it must be proven first that the sequence $\left\{\psi\left(\omega_{n}, x\right)\right\}$ is bounded from below for any $x \in\left[x_{1}, x_{4}\right]$, and then the uniform boundedness of functions $\psi\left(\omega_{n}, x\right)$ on the interval $\left[y_{1}, y_{2}\right]$.

The proof of the boundedness from below of the sequence $\left\{\psi\left(\omega_{n}, x\right)\right\}$ for any $x \in\left[x_{1}, x_{4}\right]$ is hold by contradiction. Let there exist $x^{*} \in\left[x_{1}, x_{4}\right]$ for which the sequence $\left\{\psi\left(\omega_{n}, x^{*}\right)\right\}$ is unbounded from below. First of all, it must be proven that in this case, the sequence $\left\{\psi\left(\omega_{n}, x\right)\right\}$ is unbounded from below for any $x \in\left(x_{1}, x_{4}\right)$.

Consider the contrary. Then there exists a point $x^{\prime} \in\left(x_{1}, x_{4}\right)$ for which the sequence $\left\{\psi\left(\omega_{n}, x^{\prime}\right)\right\}$ is bounded. Let, for definiteness, $x^{\prime}<x^{*}$. Then, by the convexity of the function $\psi(t, x), x \in\left[x_{1}, x_{4}\right]$, for any $x^{\prime \prime} \in\left(x_{1}, x^{\prime}\right)$,

$$
\psi\left(\omega_{n}, x^{\prime}\right) \leq \alpha \psi\left(\omega_{n}, x^{\prime \prime}\right)+(1-\alpha) \psi\left(\omega_{n}, x^{*}\right),
$$

where $\alpha=\frac{x^{\prime}-x^{*}}{x^{\prime \prime}-x^{*}}$. If $\psi\left(\omega_{n}, x^{\prime \prime}\right)$ is unbounded from below, then the right-hand side of this inequality is unbounded below as the sum of two functions unbounded from below, and if $\psi\left(\omega_{n}, x^{\prime \prime}\right)$ is bounded from below, then the right-hand side of the inequality under consideration is unbounded below as the sum of functions bounded and unbounded from below, since as it is proved before, $\left\{\psi\left(\omega_{n}, x^{\prime \prime}\right)\right\}$ is bounded from above. Thus, the right-hand side of the inequality considered is unbounded from below in any of the two possible cases. So that, its left-hand side is also unbounded from below, which contradicts the assumption that $\left\{\psi\left(\omega_{n}, x^{\prime}\right)\right\}$ is bound from below. The case when $x^{\prime}>x^{*}$ can be considered in a similar way.

Thus, if the sequence $\left\{\psi\left(\omega_{n}, x^{*}\right)\right\}$ is unbounded for some $x^{*} \in\left[x_{1}, x_{4}\right]$, then for all $x \in\left(x_{1}, x_{4}\right)$ the sequence $\left\{\psi\left(\omega_{n}, x^{*}\right)\right\}$ is also unbounded from below. But then it follows from the definition of $\psi(t, x)$ that, for any $x \in\left(x_{1}, x_{4}\right)$,

$$
\lim _{n \rightarrow \infty} \phi^{\prime}\left(\omega_{n}, x\right)=0 .
$$

Moreover, this convergence is uniform on any interval $\left[l_{1}, l_{2}\right] \subset\left(x_{1}, x_{4}\right)$. The last remark is valid in view of the estimate obtained in the proof of Theorem 3,

$$
\phi^{\prime}\left(\omega_{n}, x\right) \leq\left(\phi^{\prime}\right)^{\alpha}\left(\omega_{n}, l_{1}\right)\left(\phi^{\prime}\right)^{1-\alpha}\left(\omega_{n}, l_{2}\right)
$$

valid for all $x \in\left[l_{1}, l_{2}\right]$ and $\alpha=\frac{x-l_{2}}{l_{1}-l_{2}}$. 
Suppose $l_{1} \in\left(x_{1}, x_{2}\right), l_{2} \in\left(x_{3}, x_{4}\right)$. Then, on $\left[l_{1}, l_{2}\right]$, the sequence of functions $\left\{\phi\left(\omega_{n}, x\right)\right\}$ converges uniformly to a function constant on $\left[l_{1}, l_{2}\right]$. Then,

$$
\lim _{n \rightarrow \infty} \phi\left(\omega_{n}, x_{2}\right)=\lim _{n \rightarrow \infty} \phi\left(\omega_{n}, x_{3}\right)
$$

But the specific choice of $\left\{\omega_{n}\right\}$ implies that

$$
\lim _{n \rightarrow \infty} \phi\left(\omega_{n}, x_{i}\right)=x_{i}, \quad i=1,2,3,4 .
$$

Hence $x_{2}=x_{3}$. This contradiction proves that the sequence $\left\{\psi\left(\omega_{n}, x\right)\right\}$ is bounded from below for any $x \in\left[x_{1}, x_{4}\right]$.

Now it must be proved that a set of functions $\left\{\psi\left(\omega_{n}, x\right)\right\}$ is uniformly bounded from below on $\left[y_{1}, y_{2}\right]$. Consider two points $z_{1}<z_{2}$ from $\left[x_{1}, y_{1}\right)$. Then, for any $x \in\left[y_{1}, y_{2}\right]$, due to convexity of the function $\psi(t, x)$ on $x \in\left[y_{1}, y_{2}\right]$, it follows that for $\alpha=\frac{x-z_{2}}{x-z_{1}}$,

$$
\psi\left(\omega_{n}, z_{2}\right)-\alpha \psi\left(\omega_{n}, z_{1}\right) \leq(1-\alpha) \psi\left(\omega_{n}, x\right) .
$$

Considering that

$$
1-\alpha=\frac{z_{2}-z_{1}}{x-z_{1}} \geq \frac{z_{2}-z_{1}}{y_{2}-z_{1}}>0
$$

and that the left-hand side of inequality presented above is bounded from below by a constant for all $\alpha$, the required conclusion is obtained.

Thus, it is shown that functions $\psi\left(\omega_{n}, x\right)$ taken on an arbitray interval $\left[y_{1}, y_{2}\right] \subset\left(x_{1}, x_{4}\right)$ are uniformly bounded both from above and below, and therefore are uniformly bounded.

Theorem 8. If Equation (10) has four almost periodic solutions $\phi\left(t, x_{i}\right), i=1,2,3,4$, then the functions $\psi\left(\omega_{n}, x\right), x \in\left[y_{1}, y_{2}\right]$ are equicontinuous for any interval $\left[y_{1}, y_{2}\right] \subset\left(x_{1}, x_{4}\right)$.

Proof. Consider an arbitrary interval $\left[y_{1}, y_{2}\right] \subset\left(x_{1}, x_{4}\right)$ and two points $z_{1}<z_{2}$ in it. Assume:

$$
m=\frac{1}{2}\left(y_{2}+x_{4}\right) \text {. }
$$

Since $\psi(t, x)$ is a function convex on $\left[x_{1}, x_{4}\right]$, then the function $\frac{\psi\left(\omega_{n}, y\right)-\psi\left(\omega_{n}, x\right)}{y-x}, x, y \in\left[x_{1}, x_{4}\right]$ is increasing with respect to $y$ for any $n[3]$. Then,

$$
\begin{aligned}
& \frac{\psi\left(\omega_{n}, z_{2}\right)-\psi\left(\omega_{n}, z_{1}\right)}{z_{2}-z_{1}} \leq \frac{\psi\left(\omega_{n}, m\right)-\psi\left(\omega_{n}, z_{1}\right)}{m-z_{1}} \\
& \leq \frac{\left|\psi\left(\omega_{n}, m\right)\right|+\left|\psi\left(\omega_{n}, z_{1}\right)\right|}{m-y_{2}} .
\end{aligned}
$$

In Theorem 7 it is shown that the sequence $\left\{\psi\left(\omega_{n}, m\right)\right\}$ is bounded, and that the functions $\psi\left(\omega_{n}, z_{1}\right)$ are uniformly bounded for $z_{1} \in\left[y_{1}, y_{2}\right]$. Taking this into account, the following inequality is obtained:

$$
\frac{\psi\left(\omega_{n}, z_{2}\right)-\psi\left(\omega_{n}, z_{1}\right)}{z_{2}-z_{1}} \leq \frac{\left|\psi\left(\omega_{n}, m\right)\right|+\left|\psi\left(\omega_{n}, z_{1}\right)\right|}{m-y_{2}} \leq K,
$$

which holds for all $n$.

It can be proved in a similar way that there exists a finite $L$ such that for all $n$ and any $z_{1}$ and $z_{2}$ in $\left[y_{1}, y_{2}\right]$

$$
\frac{\psi\left(\omega_{n}, z_{2}\right)-\psi\left(\omega_{n}, z_{1}\right)}{z_{2}-z_{1}} \geq L
$$


Consider now an arbitrary $\varepsilon>0$ and assume that

$$
\delta=\frac{\varepsilon}{\max (|K|,|L|)} .
$$

Then for all $n$ and any $z_{1}$ and $z_{2}$ from $\left[y_{1}, y_{2}\right]$ such that $\left|z_{2}-z_{1}\right|<\delta$,

$$
\left|\psi\left(\omega_{n}, z_{2}\right)-\psi\left(\omega_{n}, z_{1}\right)\right| \leq \max (|K|,|L|)\left|z_{2}-z_{1}\right| \leq \varepsilon .
$$

This proves that the functions $\psi\left(\omega_{n}, x\right)$ are equicontinuous on an arbitrarily taken interval $\left[y_{1}, y_{2}\right] \subset\left(x_{1}, x_{4}\right)$.

Without loss of generality, it can assumed that the function $f(t, x)$ on the right-hand side of Equation (10) is such that $t^{*}>0$ for it, where $t^{*}$ is the moment at which the function $f^{\prime}(t, x)$ is strictly convex with respect to $x$. Then, it follows from the proof of Theorem 3 [32] that the functions $\psi\left(\omega_{n}, x\right)$ are strictly convex on $\left[x_{1}, x_{4}\right]$ for all $n$ for which $\omega_{n}>t^{*}$. Theorems 7 and 8 prove that the sequence of functions $\left\{\psi\left(\omega_{n}, x\right)\right\}$ satisfies all the requirements of the Arzela-Ascoli theorem at an arbitrarily taken interval $\left[y_{1}, y_{2}\right] \subset\left(x_{1}, x_{4}\right)$. Hence, this sequence can be assumed to be uniformly convergent to a continuous function $\psi(x)$ on $\left[y_{1}, y_{2}\right]$. Note that starting from some number $N$ all functions $\psi\left(\omega_{n}, x\right)$ are strictly convex for $n>N$.

Theorem 9. If Equation (10) has four almost periodic solutions, then the sequence of functions $\left\{\psi\left(\omega_{n}, x\right)\right\}$ converges to a strictly convex function $\psi(x)$ on any interval $\left[y_{1}, y_{2}\right] \subset\left(x_{1}, x_{4}\right)$.

Proof. Since the functions $\psi\left(\omega_{n}, x\right)$ are convex and uniformly convergent on an arbitrarily chosen interval $\left[y_{1}, y_{2}\right] \subset\left(x_{1}, x_{4}\right)$, the function $\psi(x)$ is convex on $\left[y_{1}, y_{2}\right]$. If $\psi(x)$ is assumed to be not strictly convex, then there exists an interval $\left[z_{1}, z_{2}\right] \subset\left[y_{1}, y_{2}\right]$ for which

$$
\psi(x)=a x+b,
$$

where $a$ and $b$ are constants. Consider now the functions $\psi\left(\omega_{n}, x\right)$ on an interval $\left[z_{1}, z_{2}\right]$.

Consider also four points in $\left[z_{1}, z_{2}\right]$

$$
l_{1}<l_{2}<l_{3}<l_{4}
$$

and the right derivative of function $\psi\left(\omega_{n}, x\right)$. This derivative exists and is finite by convexity of $\psi\left(\omega_{n}, x\right)$.

It follows from Theorem 12 [31] that there exist two sequences $\left\{\zeta_{1}\left(\omega_{n}\right)\right\}$ and $\left\{\zeta_{2}\left(\omega_{n}\right)\right\}$ such that $\zeta_{1}\left(\omega_{n}\right) \in\left(l_{1}, l_{2}\right), \zeta_{2}\left(\omega_{n}\right) \in\left(l_{3}, l_{4}\right)$ for all $n$ and the following inequalities are realised:

$$
\psi\left(\omega_{n}, l_{2}\right)-\psi\left(\omega_{n}, l_{1}\right) \leq \psi^{\prime+}\left(\omega_{n}, \zeta_{1}\left(\omega_{n}\right)\right)\left(l_{2}-l_{1}\right)
$$

and

$$
\psi\left(\omega_{n}, l_{4}\right)-\psi\left(\omega_{n}, l_{3}\right) \geq \psi^{\prime+}\left(\omega_{n}, \zeta_{2}\left(\omega_{n}\right)\right)\left(l_{4}-l_{3}\right) .
$$

However,

$$
\begin{aligned}
& \lim _{n \rightarrow \infty}\left[\psi\left(\omega_{n}, l_{2}\right)-\psi\left(\omega_{n}, l_{1}\right)\right]=a\left(l_{2}-l_{1}\right), \\
& \lim _{n \rightarrow \infty}\left[\psi\left(\omega_{n}, l_{4}\right)-\psi\left(\omega_{n}, l_{3}\right)\right]=a\left(l_{4}-l_{3}\right),
\end{aligned}
$$

and therefore

$$
\begin{aligned}
& \lim _{n \rightarrow \infty} \psi^{\prime+}\left(\omega_{n}, \zeta_{1}\left(\omega_{n}\right)\right) \geq a, \\
& \lim _{n \rightarrow \infty} \psi^{\prime+}\left(\omega_{n}, \zeta_{2}\left(\omega_{n}\right)\right) \leq a .
\end{aligned}
$$


Taking into account that for each $n$

$$
\psi^{\prime+}\left(\omega_{n}, \zeta_{1}\left(\omega_{n}\right)\right) \leq \psi^{\prime+}\left(\omega_{n}, \zeta_{2}\left(\omega_{n}\right)\right),
$$

the following is obtained:

$$
\lim _{n \rightarrow \infty} \psi^{\prime+}\left(\omega_{n}, \zeta_{1}\left(\omega_{n}\right)\right)=\lim _{n \rightarrow \infty} \psi^{\prime+}\left(\omega_{n}, \zeta_{2}\left(\omega_{n}\right)\right)=a .
$$

Moreover, since for any $x \in\left[l_{2}, l_{3}\right]$,

$$
\psi^{\prime+}\left(\omega_{n}, \zeta_{1}\left(\omega_{n}\right)\right) \leq \psi^{\prime+}\left(\omega_{n}, x\right) \leq \psi^{\prime+}\left(\omega_{n}, \zeta_{2}\left(\omega_{n}\right)\right),
$$

then for $x \in\left[l_{2}, l_{3}\right]$

$$
\lim _{n \rightarrow \infty} \psi^{\prime+}\left(\omega_{n}, x\right)=a .
$$

Moreover, this convergence is uniform with respect to $x$.

Let $\lambda^{+}\left[\psi^{\prime+}\right]\left(\omega_{n}, x\right)$ be an arbitrary right derived number of the function $\psi^{\prime+}\left(\omega_{n}, x\right)$ at a point $x \in\left[l_{2}, l_{3}\right]$, and let $\left\{h_{q}\right\}$ be the sequence on which this derived number is realized for $h_{q} \rightarrow 0$ as $q \rightarrow \infty, h_{q}>0$. Let us fix some $n>N$. Then for any natural number $p$

$$
\begin{aligned}
& \lambda^{+}\left[\psi^{\prime+}\right]\left(\omega_{n+p}, x\right)=\lim _{q \rightarrow \infty} \frac{1}{h_{q}} \int_{0}^{\omega_{n+p}} \phi^{\prime}\left(t, x+h_{q}\right)\left[\left(f^{\prime}\right)^{\prime+}\left(t, \phi\left(t, x+h_{q}\right)\right)\right. \\
& \left.-\left(f^{\prime}\right)^{\prime+}(t, \phi(t, x))\right] d t+\frac{1}{2} \psi^{\prime+2}\left(\omega_{n+p}, x\right) \geq \lim _{q \rightarrow \infty} \frac{1}{h_{q}} \int_{0}^{\omega_{n}} \phi^{\prime}\left(t, x+h_{q}\right)\left[\left(f^{\prime}\right)^{\prime+}\left(t, \phi\left(t, x+h_{q}\right)\right)-\right. \\
& \left.\left(f^{\prime}\right)^{\prime+}(t, \phi(t, x))\right] d t \geq m \lim _{q \rightarrow \infty} \frac{1}{h_{q}} \int_{0}^{\omega_{n}}\left[\left(f^{\prime}\right)^{\prime+}\left(t, \phi\left(t, x+h_{q}\right)\right)-\left(f^{\prime}\right)^{\prime+}(t, \phi(t, x))\right] d t=r^{\prime+}(x) \geq 0 .
\end{aligned}
$$

Then

$$
m=\min _{t \in\left[0, \omega_{n}\right], x \in\left[l_{2}, l_{3}\right], h \in[0, \delta]} \phi^{\prime}(t, x+h)>0,
$$

where $\delta>0$ is a sufficiently small constant, and

$$
r(x)=m \int_{0}^{\omega_{n}}\left(f^{\prime}\right)^{\prime+}(t, \phi(t, x)) d t .
$$

Repeating the arguments given in the proof of Theorem 3 [32], it is easy to prove that $r(x)$ strictly increases on $\left[l_{2}, l_{3}\right]$. Then it can be represented as

$$
r(x)=r_{1}(x)+r_{2}(x),
$$

where $r_{1}(x)$ is a continuous function, and $r_{2}(x)$ is a function of the function $r(x)$ jumps. It is easy to verify that $r_{1}$ strictly increases on $\left[l_{2}, l_{3}\right]$, and for any $x \in\left[l_{2}, l_{3}\right]$

$$
r^{\prime+}(x) \geq r_{1}^{\prime+}(x) .
$$

Consider now the function

$$
s\left(\omega_{n+p}, x\right)=\psi^{\prime+}\left(\omega_{n+p}, x\right)-r_{1}(x), \quad x \in\left[l_{2}, l_{3}\right] .
$$

It follows from the estimates obtained above that all the right derived numbers of a function $s$ for any finite $p$ are nonnegative, and the function $s$ itself does not have jumps down, since $\psi^{\prime+}$ increases, and $r_{1}$ is continuous. Hence, taking into account the Theorem 9 proposition in [33], it can be concluded that for each finite $p$ the function $s$ increases with respect to $x$. So that, $s\left(\omega_{n+p}, x\right)$ has a derivative almost everywhere in $\left[l_{2}, l_{3}\right]$. Let us define $s^{\prime}\left(\omega_{n+p}, x\right)$ for all points $x \in\left[l_{2}, l_{3}\right]$, assuming that $s^{\prime}\left(\omega_{n+p}, x\right)=0$ at those points $x$ in which $s\left(\omega_{n+p}, x\right)$ has no derivative. 
For a function $s^{\prime}$ defined in this way and for any finite $p$, the following inequality is realised:

$$
s\left(\omega_{n+p}, l_{3}\right)-s\left(\omega_{n+p}, l_{2}\right) \geq \int_{l_{2}}^{l_{3}} s^{\prime}\left(\omega_{n+p}, x\right) d x \geq 0 .
$$

Taking into account the definition of the function $s$, it can be obtained from the inequality given above that for any finite $p$

$$
\begin{aligned}
& \psi^{\prime+}\left(\omega_{n+p}, l_{3}\right)-\psi^{\prime+}\left(\omega_{n+p}, l_{2}\right) \geq \\
& r_{1}\left(l_{3}\right)-r_{1}\left(l_{2}\right)=\varepsilon>0,
\end{aligned}
$$

which contradicts the existence of identical limits for these two sequences. Note that the inequality

$$
r_{1}\left(l_{3}\right)-r_{1}\left(l_{2}\right)>0
$$

follows from the strict increase of the function $r_{1}$ on $\left[l_{2}, l_{3}\right]$.

Thus, it is shown that there is no segment on which the function $\psi(x)$ coincides with a line segment, and, consequently, $\psi(x)$ is strictly convex on any interval $\left[y_{1}, y_{2}\right] \subset\left(x_{1}, x_{4}\right)$.

So now a theorem analogous to Theorem 3 can be proven [32].

Theorem 10. Equation (10) can not have more than three almost periodic solutions.

Proof. Let Equation (10) have four almost periodic solutions $\phi\left(t, x_{i}\right), i=1,2,3,4$. Then consider three sequences $\left\{z_{n}^{j}\right\}$,

$$
z_{n}^{j}=\max _{x \in\left[x_{j}, x_{j+1}\right]}\left|\phi\left(\omega_{n}, x\right)-x\right|, \quad j=1,2,3 .
$$

Since they are bounded, they can be considered convergent without loss of generality. Suppose that

$$
\lim _{n \rightarrow \infty} z_{n}^{j}=z^{j}, \quad j=1,2,3 \text {. }
$$

Let us prove now that for any $j=1,2,3, z^{j} \neq 0$. Let, for example, $z^{1}=0$. Then consider an arbitrary interval $\left[y_{1}, y_{2}\right] \subset\left(x_{1}, x_{2}\right)$. By Theorem 6 , the functions $\phi^{\prime}\left(t, y_{1}\right)$ and $\phi^{\prime}\left(t, y_{2}\right)$ are bounded, so that on the basis of Theorem 4 it can be concluded that a set of functions $\phi(t, x), x \in\left[y_{1}, y_{2}\right]$ is uniformly bounded and equicontinuous with respect to $x$. Taking into account Theorems 3 and 8 , it follows that the sequence of functions $\left\{\phi^{\prime}\left(\omega_{n}, x\right)\right\}, x \in\left[y_{1}, y_{2}\right]$ is also uniformly bounded and equicontinuous with respect to $x$. Considering this fact, without loss of generality, the sequences of functions $\left\{\phi\left(\omega_{n}, x\right)\right\}$ and $\left\{\phi^{\prime}\left(\omega_{n}, x\right)\right\}$, can be considered uniformly convergent to continuous functions $\phi(x)$ and $\phi^{\prime}(x)$, respectively.

The assumption that $z^{1}=0$ implies that on $\left[y_{1}, y_{2}\right]$

$$
\phi(x)=x
$$

and then

$$
\phi^{\prime}(x)=1
$$

It follows from the last identity that on $\left[y_{1}, y_{2}\right] \subset\left(x_{1}, x_{2}\right) \subset\left(x_{1}, x_{4}\right)$,

$$
\psi(x) \equiv 0 .
$$

But this is impossible, since $\psi(x)$ is strictly convex on any closed interval belonging to $\left(x_{1}, x_{4}\right)$ due to Theorem 9. This contradiction proves that $z^{1}$ can not be equal to zero. For the remaining two intervals, the arguments are similar. 
From the fact that $z^{j}>0, j=1,2,3$ it follows there exist $\delta>0$ such that for all $j=1,2,3$ :

$$
z^{j}>\delta
$$

Consider $N$ being so large that for all $n>N$ and all $j=1,2,3$, and $i=1,2,3,4$ the following relations hold:

$$
z_{n}^{j}>\frac{1}{2} \delta, \quad\left|\phi\left(\omega_{n}, x_{i}\right)-x_{i}\right|<\frac{1}{2} \delta, \quad \omega_{n}>t^{*} .
$$

Let us fix an arbitrary $n>N$. Then, by virtue of $N$ choice, the function $\left|\phi\left(\omega_{n}, x\right)-x\right|$ reaches its maximum at some internal point of this interval on each of the intervals $\left[x_{j}, x_{j+1}\right], j=1,2,3$, Therefore, in each interval $\left(x_{j}, x_{j+1}\right), j=1,2,3$ there exists a point $y_{j}$ such that

$$
\phi^{\prime}\left(\omega_{n}, y_{j}\right)=1
$$

Then, considering that

$$
\psi(t, x)=\ln \phi^{\prime}(t, x)
$$

the following is obtained:

$$
\psi\left(\omega_{n}, y_{j}\right)=0, \quad j=1,2,3
$$

So, if Equation (10) has four almost periodic solutions, then for some sufficiently large $n$ there exist three different points $y_{j}$ on $\left(x_{1}, x_{4}\right)$, each of which satisfies in each of which

$$
\psi\left(\omega_{n}, y_{j}\right)=0 .
$$

But for $x \in\left[x_{1}, x_{4}\right]$ and $\omega_{n}>t^{*}$, the function $\psi\left(\omega_{n}, x\right)$ is strictly convex, and it consequently, can not take three identical values in $\left[x_{1}, x_{4}\right]$. This contradiction proves that the assumption can not be realized.

The main results obtained here can be represented in a unified form, for which the new notation is introduced setting that

$$
\begin{gathered}
f^{-1}(t, x)=\int_{0}^{x} f(t, y) d y, \\
f^{0}(t, x)=f(t, x), \\
f^{1}(t, x)=f^{\prime}(t, x),
\end{gathered}
$$

where $f(t, x)$ is a function that is continuous in a set of arguments.

Theorem 11. If for some $k=1,2,3$ a function $f^{k-2}(t, x)$ is continuous in the set of arguments and convex with respect to $x$ for each fixed $t$, and there exists a moment $t^{*}$ such that $f^{k-2}\left(t^{*}, x\right)$ is strictly convex, then Equation (1) can have no more than $k$ almost periodic solutions.

\section{A Lower Bound for the Number of Almost Periodic Solutions}

On the basis of the previous theorems, the authors obtain the conditions to determine the maximum possible number of almost periodic solutions in first-order differential equation. Now the problem of the existence of almost periodic solutions for the equation is under consideration, since this allows for the determination of the minimum possible number of almost periodic solutions for the differential equation considered.

So, consider the first-order differential equation

$$
\dot{x}=f(t, x),
$$


where $f$ is a function continuous on $R^{2}$ that is almost periodic in $t$ uniformly in $x$ in every compact set and such that Equation (11) has the property of existence and uniqueness of its solutions.

To prove the existence of almost periodic solution for Equation (11), the result obtained in [35] should be used. Let it be formulated in the form of the following theorem.

Theorem 12. Let the right-hand side of Equation (11) be such that $f(t, x)$ decreases with respect to $x \in[a, b]$ for each fixed $t$. Then, if Equation (11) has a bounded solution $\phi(t)$ such that $\{\phi(t): 0 \leq t<\infty\} \subset[a, b]$, then it has an almost periodic solution $x(t)$ whose range of values is in the interval $[a, b]$.

Remark 1. If in Equation (11) veriable change is realized, setting $\tau=-t$, then the following equation is obtained:

$$
\frac{d x}{d \tau}=-f(-\tau, x) .
$$

It is clear that if Equation (11) has an almost periodic solution, then Equation (12) also has an almost periodic solution, and vice versa. This implies that Theorem 12 is valid if $f(t, x)$ increases with respect to $x$ for each fixed $t$.

Theorem 13. If the right-hand side of Equation (11) is a function decreasing with respect to $x$ for each fixed $t$, and

$$
\lim _{x \rightarrow-\infty} f(t, x)=+\infty
$$

and

$$
\lim _{x \rightarrow+\infty} f(t, x)=-\infty
$$

uniformly with respect to $t$, then Equation (11) has an almost periodic solution.

Proof. By virtue of the assumption that $f(t, x) \rightarrow+\infty$ as $x \rightarrow-\infty$ and $f(t, x) \rightarrow-\infty$ as $x \rightarrow+\infty$ uniformly with respect to $t$, there exist constants $K>0$ and $\alpha>0$, such that for $x<-K$

$$
f(t, x) \geq \alpha,
$$

and for $x>K$

$$
\begin{gathered}
f(t, x) \leq-\alpha, \\
x<-\left.K \frac{d}{d t}\right|_{(11)}\left(x^{2}\right)<0 .
\end{gathered}
$$

Therefore, the solution of Equation (11) starting at any point $x_{0},\left|x_{0}\right| \leq K$ can not leave the band $[-K, K]$. Thus, Equation (11) has a bounded solution, which implies that Equation (11) has at least one almost periodic solution taking into account Theorem 12.

Theorem 14. Let $f(t, x)$ decrease with respect to $x$ for each fixed $t$, and there exists a moment $t^{*}$, such that $f\left(t^{*}, x\right)$ strictly decreases. Then, in order for Equation (11) to have a unique, almost periodic solution, it is necessary and sufficient that it has at least one bounded solution.

Proof. The necessity of the theorem conditions is obvious, since if Equation (11) has an almost periodic solution, then this solution is the desired bounded solution. Let the sufficiency be proven.

If Equation (11) has a bounded solution, then the requirements of Theorem 12 hold, which implies that Equation (11) has an almost periodic solution. But, by Theorem 1, Equation (11) can not have more than one almost periodic solution if the conditions of Theorem 14 are satisfied. Integration of these two assertions implies that Equation (11) has a unique almost periodic solution due to the conditions of Theorem 14. 
Theorem 15. Let the right-hand side of Equation (11) be such that the equation

$$
f(t, \gamma(t)) \equiv 0
$$

has $n$ solutions $\gamma_{i}(t), i=1, \ldots$, with the following property: for any $k=0,1 \ldots, n$ in the domain

$$
D_{k}=\left\{(t, x): t \in(-\infty,+\infty), \gamma_{k}(t)<x<\gamma_{k+1}(t)\right\}
$$

where it is supposed $\gamma_{0}=-\infty, \gamma_{n+1}=+\infty$, the function $f(t, x)$ is constant-sign, and the sign of the function changes when passing to the neighboring domain. Then, if

$$
\begin{aligned}
& \beta_{j}=\max _{t} \gamma_{j}(t)<\min _{t} \gamma_{j+1}(t)=\alpha_{j+1}, \\
& j=1,2, \ldots, n-1,
\end{aligned}
$$

and in each domain

$$
\alpha_{i} \leq x \leq \beta_{i}
$$

the function $f(t, x)$ is increasing or decreasing with respect to $x$ for each fixed $t$, then Equation (11) has $n$ almost periodic solutions.

Proof. First of all, let us prove that if there exists bounded functions defined on $(-\infty,+\infty)$ continuously differentiable functions $\alpha(t)$ and $\beta(t)$, such that

$$
\alpha(t) \leq \beta(t)
$$

and

$$
G(\alpha)(t)=\dot{\alpha}(t)-f(t, \alpha(t)) \leq 0 \leq G(\beta)(t), t \in(-\infty,+\infty),
$$

then Equation (11) has a bounded solution.

Suppose that

$$
c(t, x)=\alpha(t), x(t)<\alpha(t) x(t), x(t) \in[\alpha(t), \beta(t)] \beta(t), x(t)>\beta(t)
$$

and consider the equation

$$
\dot{x}+x=c(t, x)+f(t, c(t, x)) .
$$

It is clear that Equation (13) turns into Equation (11) if Equation (11) has a solution $y(t)$, such that for all $t$

$$
\alpha(t) \leq y(t) \leq \beta(t)
$$

Let us prove that such a solution exists.

Consider the contrary. Then, the solution $y\left(t, y_{0}\right)$, starting at an arbitrary point $y_{0} \in[\alpha(0), \beta(0)]$, leaves the considered domain in time. For example, let it get into the domain $y(t)<\alpha(t)$. For this opportunity to be realizable, there must necessarily exist a point $t^{*}$ at which $y\left(t^{*}\right)<\alpha\left(t^{*}\right)$ and $\dot{y}\left(t^{*}\right) \leq \dot{\alpha}\left(t^{*}\right)$. In this case, from (13), the following is obtained:

$$
\dot{y}\left(t^{*}\right)-f\left(t^{*}, \alpha\left(t^{*}\right)\right)=\alpha\left(t^{*}\right)-y\left(t^{*}\right) \text {. }
$$

However,

$$
\dot{y}\left(t^{*}\right) \leq \dot{\alpha}\left(t^{*}\right)
$$

and by condition

$$
\dot{\alpha} \leq f(t, \alpha),
$$


therefore,

$$
\dot{y}\left(t^{*}\right)-f\left(t^{*}, \alpha\left(t^{*}\right)\right) \leq 0 .
$$

On the other hand,

$$
\alpha\left(t^{*}\right)-y\left(t^{*}\right)>0 .
$$

Thus, the left-hand side of Equation (14) does not exceed zero, and its right-hand side is strictly greater than zero for $t=t^{*}$.

This contradiction shows that the solution $y\left(t, y_{0}\right)$ of Equation (13) starting at a point $y_{0} \in$ $[\alpha(0), \beta(0)]$ can not get into the domain $y(t)<\alpha(t)$. Similarly, it can be proven that this solution also can not get into the domain $y(t)<\alpha(t)$. Therefore, for $t \geq 0$ the following estimation is realized:

$$
\alpha(t) \leq y(t) \leq \beta(t),
$$

which implies that there exists a bounded solution for Equation (13) and for Equation (11) as well, considering the assumption thst the functions $\alpha$ and $\beta$ are bounded.

The case when

$$
G(\alpha)(t) \geq 0 \geq G(\beta)(t)
$$

can be considered in a similar way.

Now consider an arbitrary $i=1,2,3,4$. Assume for definiteness that in the domain $D_{i-1}$

$$
f(t, x) \geq 0,
$$

and in the domain $D_{i}$

$$
f(t, x) \leq 0 .
$$

By the condition of the theorem

$$
\beta_{j}<\alpha_{j+1}, \quad j=1,2, \ldots, n-1 .
$$

Therefore, for the considered $i$ for $x \equiv \alpha_{i}$

$$
G(x)(t) \leq 0,
$$

and for $x \equiv \beta_{i}$

$$
G(x)(t) \geq 0 .
$$

Thus, all the requirements of the proved statement hold, which allows us to conclude that Equation (11) has a bounded solution in the band

$$
\alpha_{i} \leq x \leq \beta_{i}
$$

However, by assumption, the function $f(t, x)$ is monotonous and almost periodicwith respect to $t$ uniformly in $x$ in this band, i.e., in the band

$$
\alpha_{i} \leq x \leq \beta_{i}
$$

all the requirements of Theorem 12 are satisfied, which implies that Equation (11) has an almost periodic solution in the band

$$
\alpha_{i} \leq x \leq \beta_{i}
$$

Let us prove that in the band

$$
\alpha_{i} \leq x \leq \beta_{i}
$$


there can not exist two almost periodic solutions. Suppose the contrary. Let $x_{1}(t)$ denote one almost periodic solution, and $x_{2}(t)$ denote the other. Let, for definiteness, $x_{1}(0)<x_{2}(0)$. Let the difference $x_{1}(t)-x_{2}(t)$ be represented in the form

$$
x_{1}(t)-x_{2}(t)=x_{1}(0)-x_{2}(0)+\int_{0}^{t}\left[f\left(\tau, x_{1}(\tau)\right)-f\left(\tau, x_{2}(\tau)\right)\right] d \tau .
$$

$x_{1}(t)$ and $x_{2}(t)$ never intersect due to existence and uniqueness of the solutions, so that for all $t:$

$$
x_{1}(t)<x_{2}(t) .
$$

It is obvious that in the band:

$$
\alpha_{i} \leq x \leq \beta_{i}
$$

the function $f(t, x)$ decreases with respect to $x$ for each fixed $t$. Therefore, for all $t$

$$
f\left(t, x_{1}(t)\right) \geq f\left(t, x_{2}(t)\right) .
$$

Taking this into account, the following inequality can be concluded:

$$
\left[x_{1}(t)-x_{2}(t)\right]-\left[x_{1}(0)-x_{2}(0)\right]=\int_{0}^{t}\left[f\left(\tau, x_{1}(\tau)\right)-f\left(\tau, x_{2}(\tau)\right)\right] d \tau \geq 0 .
$$

In order to be an almost periodic solution $x_{1}(t)$ must necessarily get from the domain above the curve $\gamma_{i}(t)$ into the domain under the curve $\gamma_{i}(t)$. This means that there exists a time point $t^{\prime}>0$, such that

$$
x_{1}\left(t^{\prime}\right)<\gamma_{i}\left(t^{\prime}\right)<x_{2}\left(t^{\prime}\right) \text {. }
$$

But by the theorem condition

$$
f\left(t^{\prime}, \gamma_{i}\left(t^{\prime}\right)\right)=0,
$$

and a graph $\gamma_{i}(t)$ of the function is a boundary of the sign change domains of the function $f(t, x)$. Consequently, at the point the following inequality holds:

$$
f\left(t^{\prime}, x_{1}\left(t^{\prime}\right)\right)>f\left(t^{\prime}, x_{2}\left(t^{\prime}\right)\right) \text {. }
$$

Since the function $f(t, x)$ is continuous, this inequality implies that in (15), the inequality is strict for $t \geq t^{\prime}$.

Let us show that this contradicts the assumption that the solutions $x_{1}(t)$ and $x_{2}(t)$ are almost periodic. Indeed, the difference of two almost periodic functions is an almost periodic function. Consider a sequence of positive numbers $\left\{\varepsilon_{l}\right\}$ decreasing to zero and the sequence $\left\{\omega_{l}\right\}$ corresponding to it. Here $\omega_{l}$ is a $\varepsilon_{l}$-almost period of function $x_{1}(t)-x_{2}(t)$. Without the loss of generality, the sequence $\left\{\omega_{l}\right\}$ can be considered as tending to infinity as $l \rightarrow \infty$. Consider $L$ such that $\omega_{L} \geq t^{\prime}$. Then for all $l>L$

$$
\left[x_{1}\left(\omega_{l}\right)-x_{2}\left(\omega_{l}\right)\right]-\left[x_{1}(0)-x_{2}(0)\right]=\int_{0}^{\omega_{l}}\left[f\left(t, x_{1}(t)\right)-f\left(t, x_{2}(t)\right)\right] d t \geq \delta>0,
$$

which contradicts the choice of the sequence $\left\{\omega_{l}\right\}$. This contradiction proves that in the band

$$
\alpha_{i} \leq x \leq \beta_{i}
$$

there is only one almost periodic solution of Equation (11). 
But there are $n$ such bands, by the condition of the theorem, which implies that Equation (11) has $n$ almost periodic solutions when the conditions of Theorem 15 are satisfied.

\section{Stability of Almost Periodic Solutions}

Consider now stability of the the solutions of Equation (11).

Theorem 16. If the right-hand side of Equation (11) is a function decreasing with respect to $x$ for each fixed $t$, then all solutions of this equation are uniformly stable.

Proof. Let $u(t)$ be an arbitrary solution of Equation (11). Suppose the equation for $y$ is of the following form:

$$
\dot{y}=f(t, u+y)-f(t, u)=g(t, y) .
$$

Let the following function be a Lyapunov function:

$$
v(y)=\frac{1}{2} y^{2}
$$

Since $f(t, x)$ decreases with respect to $x$ at each fixed $t$, the derivative of the function (17) on the solutions of Equation (16) satisfies the inequality

$$
\left.\frac{d v}{d t}\right|_{(16)}=y g(t, y) \leq 0
$$

which implies the uniform stability of solution $y=0$ of Equation (16), and hence, solution $u(t)$ of Equation (11). Taking into account the fact that $u(t)$ is an arbitrary solution of Equation (11), it is clear the theorem is proven.

Note that the theorem implies in the conditions of Theorem 15 that all $n$ almost periodic solutions of Equation (11) are stable, either as $t \rightarrow+\infty$, or with $t \rightarrow-\infty$. fixed $t$

Let $\lambda_{x}[f](t, x)$ denote an arbitrary derived number of the function $f(t, x)$ at the point $x$ for a

Theorem 17. If there exists a constant $\alpha>0$ such that for any fixed $t$ and each derived number $\lambda_{x}[f](t, x)$

$$
\lambda_{x}[f](t, x) \leq-\alpha
$$

then all the solutions of Equation (11) are uniformly asymptotically stable in general. If it is additionally known that Equation (11) has an almost periodic solution, then all the solutions of Equation (11) are asymptotically almost periodic.

Proof. Let $u(t)$ be an arbitrary solution of Equation (11). Let a function $y$ be introduced, setting that

$$
y=x-u
$$

It is clear that if $x$ is a solution of Equation (11), then $y$ is a solution of Equation (16). Let us obtain a derivative of Function (17) on solutions of Equation (16).

Repeating the proof of Theorem 12 [31], it is easy to show that there exist derived numbers for which the following relation holds:

$$
\begin{aligned}
& f(t, y+u)-f(t, u) \leq y \lambda_{u+\theta y}[f](t, u+\theta y) \\
& \theta \in(0,1 .)
\end{aligned}
$$


Taking into account that by the condition of the theorem

$$
\lambda_{u+\theta y}[f](t, u+\theta y) \leq-\alpha,
$$

the following estimation is obtained:

$$
\left.\frac{d v}{d t}\right|_{(16)} \leq-\alpha y^{2} .
$$

It follows from this inequality that the solution $y=0$ of Equation (16) is uniformly asymptotically stable, as well as the solution of Equation (11). Since $u(t)$ is an arbitrary solution of Equation (11), all the solutions of Equation (11) are asymptotically stable.

If Equation (11) has an almost periodic solution, then all the solutions of Equation (11) are asymptotically almost periodic in the view of its uniform asymptotic.

Theorem 18. If the function $f(t, x)$ from the right-hand side of Equation (11) decreases with respect to $x$ at each fixed $t$, and on each compact set

$$
\left\{(y, u):|u| \leq u_{0}, d_{1} \leq|y| \leq d_{2}, d_{1}>0\right\},
$$

as $t \rightarrow \infty$,

$$
\operatorname{sign}(y) \int_{0}^{t}[f(\tau, y+u)-f(\tau, u)] d \tau \rightarrow-\infty
$$

uniformly, then the solution $y=0$ of Equation (16) is uniformly asymptotically stable.

Proof. Let $u(t)$ be an arbitrary bounded solution of Equation (11). Suppose that

$$
y=x-u
$$

It follows from Theorem 16 that the solution $y=0$ of Equation (16) is uniformly stable. Let us prove that all the solutions of Equation (16) tend to zero as $t \rightarrow \infty$.

Suppose the contrary. Then for some solution $y\left(t ; 0, y_{0}\right)$ of Equation (16), there exists $d>0$, such that

$$
y\left(t ; 0, y_{0}\right)>d .
$$

Here it is assumed that $y_{0}>0$, for definiteness. In the proof of Theorem 16 , it is shown that the inequality

$$
y \dot{y} \leq 0,
$$

which implies that $|y|$ does not increase on the solutions of the Equation (16). Therefore, in the considered case for $t \geq 0$,

$$
d \leq y(t) \leq y_{0}
$$

Suppose that

$$
u_{0}=\sup _{t}|u(t)| \text {. }
$$

It follows from Equation (16) that

$$
\frac{\dot{y}}{y}=\frac{g(t, y)}{y} \leq \frac{g(t, y)}{y_{0}}
$$

Hence, by virtue of the theorem,

$$
\lim _{t \rightarrow \infty} y(t) \leq \lim _{t \rightarrow \infty} y_{0} e^{1 / y_{0} \int_{0}^{t} g(\tau, y) d \tau}=0,
$$


which contradicts the introduced assumption.

The case when $y_{0}<0$ is treated in a similar way. Thus, the solution $y=0$ of Equation (16) is uniformly asymptotically stable.

\section{Conclusions}

The upper and lower bounds for the numbers of almost periodic solutions of ordinary first-order differential equations are carried out. Conditions for the existence and stability of almost periodic solutions are established.

Author Contributions: Conceptualization, S.K. and G.A.; methodology, Ivanov; validation, S.K., G.A., G.I. and A.S.; formal analysis, G.A.; investigation, A.S.; writing—original draft preparation, G.I.; writing-review and editing, S.K.

Funding: This research received no external funding.

Conflicts of Interest: The authors declare no conflict of interest.

\section{References}

1. Lebedeva, V.M. The number of periodic solutions of a first order equation with rational right hand side. Differ. Uravn. 1969, 5, 560-562.

2. Franco, T.; Gonçalves, P.; Neumann, A. Corrigendum to "Phase transition in equilibrium fluctuations of symmetric slowed exclusion". Stoch. Process. Appl. 2016, 126, 3235-3242. [CrossRef]

3. Poincare, A. New Modis Caelestis Mechanica; Nauka: Moscow, Russia, 1971; p. 772.

4. Lyapunov, A.M. Communi Stabilitatem Motus; Gostehizdat: Moscow, Russia, 1950.

5. Pliss, V.A. Nelockalnye Problemy Teorii Kolebaniy; Nauka: Moscow, Russia, 1964; p. 367. (In Russian)

6. Ivanov, G.; Alferov, G.; Gorovenko, P.; Sharlay, A. Estimation of periodic solutions number of first-order differential equations. AIP Conf. Proc. 2018, 1959, 080006. [CrossRef]

7. Ivanov, G.; Alferov, G.; Gorovenko, P. Integrability of nonsmooth one-variable functions. In Proceedings of the 2017 Constructive Nonsmooth Analysis and Related Topics (Dedicated to the Memory of V.F. Demyanov)—CNSA 2017, St. Petersburg, Russia, 22-27 May 2017. [CrossRef]

8. Knobloch, H.W. Michigan. Math. J. 1962, N9, 303-309.

9. Mawhin, J. Periodic solutions of nonlinear functional differential equations. J. Differ. Equ. 1971, 10, $240-261$. [CrossRef]

10. Kadry, S.; Alferov, G.; Ivanov, G.; Sharlay, A. Derived numbers of one variable functions. AIP Conf. Proc. 2019, in print.

11. Kadry, S.; Alferov, G.; Ivanov, G.; Sharlay, A. Periodic solutions of the first-order differential equations. AIP Conf. Proc. 2019, in print.

12. Alferov, G.; Ivanov, G.; Sharlay, A.; Fedorov, V. Application of derived numbers theory in convex analysis. AIP Conf. Proc. 2019, in print.

13. Alferov, G.; Ivanov, G.; Sharlay, A.; Fedorov, V. Application of derived numbers theory in problem of function extremum. AIP Conf. Proc. 2019, in print.

14. Jiang, D.P. Almost periodic solutions of some first-order differential equations. Differ. Equ. 1986, 2, 11-27.

15. Kulakov, F.; Alferov, G.; Efimova, P. Methods of remote control over space robots. In Proceedings of the 2015 International Conference on Mechanics—Seventh Polyakhov's Reading, Saint Petersburg, Russia, 2-6 February 2015.

16. Efimova, P.; Shymanchuk, D. Dynamic Model of Space Robot Manipulator. Appl. Math. Sci. 2015, 9, 4653-4659. [CrossRef]

17. Kulakov, F.; Sokolov, B.; Shalyto, A.; Alferov, G. Robot Master Slave and Supervisory Control with Large Time Delays of Control Signals and Feedback. Appl. Math. Sci. 2016, 10, 1783-1796. [CrossRef]

18. Alferov, G.V.; Malafeyev, O.A. The Robot Control Strategy in a Domain with Dynamical Obstacles. In Reasoning with Uncertainty in Robotics; Lecture Notes in Computer Science (Including subseries Lecture Notes in Artificial Intelligence and Lecture Notes in Bioinformatics); Springer: Berlin/Heidelberg, Germany, 1996; Volume 1093, pp. 211-217. 
19. Kulakov, F.; Alferov, G.V.; Efimova, P.; Chernakova, S.; Shymanchuk, D. Modeling and control of robot manipulators with the constraints at the moving objects. In Proceedings of the 2015 International Conference on "Stability and Control Processes" in Memory of V.I. Zubov-SCP 2015, St. Petersburg, Russia, 5-9 October 2015; pp. 102-105. [CrossRef]

20. Alferov, G.V.; Malafeyev, O.A.; Maltseva, A.S. Programming the Robot in Tasks of Inspection and Interception. In Proceedings of the 2015 International Conference on Mechanics-Seventh Polyakhov's Reading, Saint Petersburg, Russia, 2-6 February 2015.

21. Malafeyev, O.; Alferov, G.; Andreyeva, M. Group strategy of robots in game-theoretic model of interception with incomplete information. In Proceedings of the 2015 International Conference on Mechanics-Seventh Polyakhov's Reading, Saint Petersburg, Russia, 2-6 February 2015. [CrossRef]

22. Alferov, G.; Ivanov, G.; Efimova, P.; Sharlay, A. Study on the structure of limit invariant sets of stationary control systems with nonlinearity of hysteresis type. AIP Conf Proc. 2017, 1863, 080003.

23. Malafeyev, O.A.; Nemnyugin, S.A.; Alferov, G.V. Charged particles beam focusing with uncontrollable changing parameters. In Proceedings of the 2014 2nd International Conference on Emission ElectronicsICEE 2014, Joined with 10th International Vacuum Electron Sources Conference (IVESC 2014), International Conference on Computer Technologies in Phisical and Engineering Applications (ICCTPEA 2014), 20th International Workshop on Beam Dynamics and Optimization (BDO 2014), St. Petersburg, Russia, 30 June-4 July 2014.

24. Pichugin, Y.; Alferov, G.; Malafeyev, O. Parameters estimation in mechanism design. Contemp. Eng. Sci. 2016, 9, 175-185. [CrossRef]

25. Alferov, G.V.; Ivanov, G.G.; Efimova, P.A. The Structural Study of Limited Invariant Sets of Relay Stabilized Systems. In Mechanical Systems: Research, Applications and Technology; Nova Science Publishers: New York, NY, USA, 2017; pp. 101-164.

26. Malafeyev, O.A.; Neverova, E.G.; Nemnyugin, S.A.; Alferov, G.V. Multi-criteria model of laser radiation control. In Proceedings of the 2014 2nd International Conference on Emission Electronics-ICEE 2014, Joined with 10th International Vacuum Electron Sources Conference (IVESC 2014), International Conference on Computer Technologies in Physical and Engineering Applications (ICCTPEA 2014), 20th International Workshop on Beam Dynamics and Optimization (BDO 2014), St. Petersburg, Russia, 30 June-4 July 2014.

27. Alferov, G.V.; Ivanov, G.G.; Efimova, P.A.; Sharlay, A.S. Stability of linear systems with Multitask Right-hand Member. In Stochastic Methods for Estimation and Problem Solving in Engineering; IGI Global: Hershey, PA, USA, 2018; pp. 74-112.

28. Kadry, S.; Alferov, G.; Ivanov, G.; Sharlay, A. About Stability of Selector Linear Differential Inclusions. AIP Conf. Proc. 2019, in print.

29. Ivanov, G.G.; Sharlay, A.S. On stability of linear homogeneous switched systems. In Proceedings of the 2015 International Conference "Stability and Control Processes" in Memory of V.I. Zubov (SCP), St. Petersburg, Russia, 5-9 October 2015; pp. 13-15.

30. Kadry, S.; Alferov, G.; Ivanov, G.; Sharlay, A. Stabilization of the program motion of control object with elastically connected elements. AIP Conf. Proc. 2019, in print.

31. Ivanov, G.G.; Alferov, G.V.; Sharlay, A.S.; Efimova, P.A. Conditions of Asymptotic Stability for Linear Homogeneous Switched Systems. AIP Conf. Proc. 2017, 1863, 080002. [CrossRef]

32. Kulakov, F.; Kadry, S.; Alferov, G.; Sharlay, A. Bilateral remote control over space manipulators. AIP Conf. Proc. 2019, in print.

33. Kulakov, F.; Alferov, G.; Sokolov, B.; Gorovenko, P.; Sharlay, A. Dynamic analysis of space robot remote control system. AIP Conf. Proc. 2018, 1959, 080014. [CrossRef]

34. Kadry, S.; Alferov, G.; Kondratyuk, A.; Kurochkin, V.; Zhao, S. Modeling the motion of a space manipulation robot using position control. AIP Conf. Proc. 2019, in print.

35. Alferov; Gorizontov, A. Resource management in flexible automated production. Kibernetika $i$ Vychislitel'naya Tekhnika 1987, 73, 76-81.

36. Alferov, G.V.; Malafeyev, O.A.; Maltseva, A.S. Game-theoretic model of inspection by anti-corruption group. AIP Conf. Proc. 2015, 1648, 450009. [CrossRef] 
37. Neverova, E.G.; Malafeyev, O.A.; Alferov, G.V.; Smirnova, T.E. Model of interaction between anticorruption authorities and corruption groups. In Proceedings of the 2015 International Conference "Stability and Control Processes" in Memory of V.I. Zubov (SCP), St. Petersburg, Russia, 5-9 October 2015; pp. 488-490. [CrossRef]

38. Malafeyev, O.A.; Redinskikh, N.D.; Alferov, G.V. Electric circuits analogies in economics modeling: Corruption networks. In Proceedings of the 2014 2nd International Conference on Emission ElectronicsICEE 2014, Joined with 10th International Vacuum Electron Sources Conference (IVESC 2014), International Conference on Computer Technologies in Physical and Engineering Applications (ICCTPEA 2014), 20th International Workshop on Beam Dynamics and Optimization (BDO 2014), St. Petersburg, Russia, 30 June-4 July 2014. [CrossRef]

(C) 2018 by the authors. Licensee MDPI, Basel, Switzerland. This article is an open access article distributed under the terms and conditions of the Creative Commons Attribution (CC BY) license (http:// creativecommons.org/licenses/by/4.0/). 